\title{
NEGÓCIOS PORTUGUESES NO RIO DE JANEIRO: UM ESTUDO SOBRE O BANCO PORTUGUÊS DO BRASIL (1918 A 1938) $\left.{ }^{(*)}\right)^{(*)}$
}

\author{
Teresa Cristina de Novaes Marques ${ }^{\star * *}$
}

Hildete Pereira de Melo ${ }^{\star * * *}$

\begin{abstract}
RESUMO: Este estudo explora a rede de negócios formada a partir do Banco Português do Brasil, constituído no Rio de Janeiro por integrantes da comunidade de imigrantes portugueses residentes na cidade. As atividades do banco são observadas por 20 anos, período no qual a economia da cidade sofreu expressivas mudanças, pois os negócios de importação, articulados em torno do porto, deram lugar a investimentos voltados para o mercado interno. $\mathrm{O}$ estudo explora, também, as conexões entre grupos empresariais do Rio de Janeiro e de Lisboa, buscando mostrar a importância do capital levantado em empreendimentos no Brasil para a sustentação de negócios em Portugal.
\end{abstract}

PALAVRAS-CHAVE: bancos privados; imigração lusa; investimento.

CLASSIFICAÇÃO JEL: N26.

* Artigo recebido em 16/09/2011 e aprovado em 10/01/2012.

** Uma versão deste artigo foi apresentada por Marques na conferência “35th Annual Economic \& Business Historical Society Conference”, realizada na cidade de Braga, Portugal, em maio de 2010. A participação da autora no evento contou com apoio da Fundação de Empreendimentos Científicos e Tecnológicos, Finatec.

*** Doutora em História Social pela Universidade de Brasília e professora adjunta do Departamento de História da mesma instituição. Contato: tcnmarques@uol.com.br.

${ }^{\star * * \star}$ Doutora em Economia pela Universidade Federal do Rio de Janeiro e professora associada da Faculdade de Economia da Universidade Federal Fluminense. Contato: hildete43@gmail.com. 


\title{
PORTUGUESE BUSINESS IN RIO DE JANEIRO: EXPLORATIONS ON BANCO PORTUGUÊS DO BRASIL, 1918 TO 1938
}

\begin{abstract}
The article explores a business network that was formed from the Banco Português do Brasil. This network was formed in Rio de Janeiro by members of portuguese immigrant community. It observes the activities of the bank for twenty years, a period of time when the Rio's economy suffered drastic changes, once import businesses, organized around the City harbor gave place to investments oriented to the domestic market. The article also explores the links between entrepreneurial groups in Rio de Janeiro and Lisbon, aiming at showing the importance of the capital raised in business ventures in Brazil to leverage business in Portugal.
\end{abstract}

KEYWORDS: private banking; Portuguese immigration; investment. 


\section{INTRODUÇÃO}

Buscamos neste artigo contribuir com a historiografia brasileira e portuguesa para ampliar a compreensão sobre o alcance e a dinâmica dos negócios de imigrantes portugueses fixados na cidade do Rio de Janeiro, então a capital federal do país.

Pretende-se oferecer novos elementos para o debate sobre os arranjos institucionais do crédito a partir do exame da trajetória econômica do Banco Português do Brasil, criado em 1918, estendendo a análise até o ano de 1938, quando houve a transferência do seu controle acionário.

O Banco Português foi formado no Rio de Janeiro como o braço financeiro de proeminentes homens de negócio da comunidade portuguesa da cidade, onde predominavam famílias com ramificações empresariais no Brasil e em Portugal. Os estatutos de criação da empresa previam a atuação no mercado de intermediação de remessa de imigrantes residentes na cidade, no auxílio creditício à indústria e ao comércio. De fato, a análise dos balanços do banco demonstra que, efetivamente, alguns de seus acionistas foram contemplados com empréstimos para seus projetos industriais, o que será explorado oportunamente.

O Banco Português não foi um projeto empresarial efêmero, que desapareceu no cenário econômico do país durante a crise dos anos 1930. Ao contrário, a confiança depositada pela expressiva comunidade portuguesa residente no Brasil no banco contribuiu para que a instituição existisse autonomamente até 1973. Nesse ano, por injunções da política econômica dos governos militares, desejosos de promover uma reforma bancária visando a elevar o grau de concentração bancária, as autoridades econômicas forçaram a incorporação do Banco Português do Brasil pelo Banco Itaú, cujos maiores acionistas eram os integrantes da família Setúbal, também de origem portuguesa $^{1}$. Sobre o episódio, comentou o banqueiro Olavo Setúbal, em entrevista, que "[A] criação de unidades muito grandes foi favorecida pelas autoridades... o Banco Central permitiu determinadas vantagens fiscais”2.

\footnotetext{
${ }^{1}$ Sindicato de Bancos do Estado do Rio de Janeiro, Prontuários do Banco Português do Brasil e do Banco Itaú. A incorporação Banco Português pelo Itaú resultou de uma ampla reforma bancária, iniciada em 1964, com a Lei no 4.595/64, que criou o Banco Central do Brasil e o Conselho Monetário Nacional, secundada pela Lei no 4.728/65 do mercado de capitais. Ambas editadas pelo governo Castello Branco, primeiro governo militar. Entre 1969 e 1973, na gestão do Ministro da Fazenda Antônio Delfim Netto, nos governos dos generais Costa Silva e Médici, a Fazenda incentivou um generoso processo de formação de conglomerados financeiros que, devido ao vigoroso crescimento da economia nacional, e da desenfreada acumulação financeira, provocou uma onda de fusões e incorporações no sistema bancário brasileiro. Sobre o assunto, ver Tavares e Assis (1986).

${ }^{2}$ Entrevista de Olavo Setúbal à Revista Visão, 29 de abril de 1974, p. 90, citada por Macarini (2007).
} 
A escolha por este tema se justifica em função da importância demográfica da imigração lusitana para o Brasil, pois esse grupo social constituiu a segunda maior população imigrante no país e o maior grupo de estrangeiros residente na cidade do Rio de Janeiro na primeira metade do século $\mathrm{XX}^{3}$. Além do seu peso demográfico, ressalte-se que esses imigrantes atuaram em variados ramos de negócios na cidade do Rio, desde pequenos empreendimentos de varejo a indústrias e empresas financeiras.

A despeito dessas razões e da bibliografia já mencionada sobre a imigração portuguesa, o conhecimento histórico acerca da dinâmica dos negócios de imigrantes portugueses no Brasil é insuficiente. Da mesma forma, o debate historiográfico acerca do papel dos bancos privados no crescimento de grupos empresariais no país também carece de maior volume de pesquisas ${ }^{4}$. Particularmente, nos países das Américas que receberam expressivos contingentes de imigrantes europeus entre meados do século XIX e princípios do século XX, historiadores investigam a organização de negócios bancários por imigrantes ${ }^{5}$. No Brasil, a já escassa historiografia bancária privilegia a atuação do Banco do Brasil e confere pouca atenção ao financiamento de negócios das comunidades imigrantes nas principais cidades.

Pelo estudo comparado da dinâmica de comunidades imigrantes nas Américas, sabe-se que os negócios de crédito podiam assumir o caráter de empréstimos informais, pessoa a pessoa, nos limites da agiotagem. Imigrantes veteranos e já estabelecidos na praça podiam financiar o estabelecimento comercial de outro patrício recém-chegado, mediante o compromisso de fidelidade mercantil. Também surgiram cooperativas de crédito, e mesmo as populares associações de fundo mútuo podiam estender crédito aos afiliados. Nessa linha, convém investigar as não tão numerosas, mas igualmente importantes, organizações constituídas como bancos e casas bancárias - organizações essas revestidas das formalidades legais e voltadas para atender a comunidade imigrante, uma parcela da população que geralmente estava excluída do mercado formal do crédito por não oferecer sólidas garantias patrimoniais, a exemplo do que se observou na cidade de Nova York (Van Horn, 2010).

\footnotetext{
${ }^{3}$ Sobre imigração portuguesa para o Brasil, ver: Marques e Melo (2008), Matos (2008), Lobo (2001), CEPESE (2001).

${ }^{4}$ Sobre bancos e crescimento econômico entre fins do século XIX a meados do século XX, ver Saes (1986) e Triner (2000).

${ }^{5}$ Sobre solidariedades e negócios entre famílias de imigrantes na costa leste norte-americana, ver Smith (1985). Igualmente, sobre negócios bancários nas comunidades imigrantes, ver Day (2002).
} 
Ainda sobre o crédito, estudos enfatizam a importância dos elos de confiança entre os agentes econômicos - os credores e os emprestadores ${ }^{6}$. Mesmo na atualidade, quando a legislação oferece maior amparo aos credores no recebimento das quantias emprestadas, um devedor precisa oferecer bens em garantia, bem como demonstrar ter histórico de bom pagador. Igualmente, os depositantes pautam a escolha da instituição bancária à qual confiar a guarda de valores na reputação pública da instituição. Portanto, se hoje uma parcela do comportamento dos agentes econômicos continua a ser explicada por critérios subjetivos de decisão, esse fator é ainda mais importante para compreender as práticas creditícias nas primeiras décadas do século XX. Eis porque o estudo explora tanto o desempenho econômico da instituição quanto a imagem pública dos seus dirigentes.

Em termos metodológicos, a investigação dos primeiros anos de atividade do banco se inspira na formulação de Flávio Saes, para quem, o estudo de instituições de crédito deve superar a mera descrição das condições de oferta e demanda de moeda e explorar os vínculos das empresas financeiras com empresas produtivas (Saes, 1986, p. 49). A essa hipótese de trabalho, acrescentaríamos que o estudo do crédito requer a reconstituição das redes políticas e de negócios em que se inserem os empresários. No caso do Banco Português, seus principais acionistas participavam da porção mais destacada da comunidade portuguesa de negócios no Rio de Janeiro, com ramificações em empresas têxteis, no grande comércio importador-exportador, em empresas de seguro e de incorporação imobiliária. O banco serviu, também, de canal de transferência de ativos entre o Brasil e Portugal, país carente de capitais, como reconhece a recente historiografia lusa (Esteves, 2003).

A reconstrução da trajetória do banco está baseada nos estatutos da organização, nos relatórios anuais, nas atas de assembleias ordinárias e extraordinárias de acionistas. Tais documentos foram em parte obtidos no arquivo da Junta Comercial do Rio de Janeiro (JUCERJA), em parte extraídos do Diário Oficial. No desenvolvimento da investigação, as atas de assembleias esclareceram o encaminhamento dos negócios, as discussões entre os acionistas sobre os rumos do banco e a predominância política do grupo diretor, nas várias fases da existência da empresa. Já os balanços do banco ofereceram indicadores de resultados, apesar da escrituração se mostrar pouco clara (Marques, 1998).

Adverte-se que a documentação compulsada oferece vantagens e também problemas. Positivamente, a documentação apresenta razoável continuidade, o que

\footnotetext{
${ }^{6}$ Trata-se de uma linha de investigação bastante explorada pela historiografia do crédito no mundo lusobrasileiro, a exemplo dos trabalhos de Maria Manuela Rocha. Dessa autora, ver Rocha (2001). Ver também Madureira (1994).
} 
permite reconstituir a trajetória da instituição por duas décadas. No entanto, em se tratando de documentos divulgados ao público por imposição legal, as informações obtidas nos Diários Oficiais e nos arquivos da Junta Comercial não revelam toda a dinâmica do processo decisório interno ao banco. Ainda assim, são as fontes possíveis para realizar o exercício investigativo, na ausência da documentação primária do Banco, hoje desaparecida.

Como último ponto a ser explorado nesta seção introdutória, cabe destacar a estrutura deste trabalho. $\mathrm{O}$ artigo inicia com a discussão sobre a formação do banco e seu desenvolvimento até a crise mundial de 1929. Prossegue analisando o impacto da crise de 1929-1933 sobre a comunidade de negócios portuguesa do Rio de Janeiro, bem como o papel dos negócios imobiliários na formação de fortunas pessoais desses imigrantes em conjunção com as atividades bancárias.

\section{A FUNDAÇÃO E OS PRIMEIROS 10 ANOS}

A presença de imigrantes portugueses no capital comercial e bancária do Rio de Janeiro é um tema que os historiadores brasileiros ainda não esgotaram. Os autores de obra comemorativa da imigração lusa para o Brasil afirmam que, na segunda metade do século XIX, várias casas bancárias surgiram com o concurso de capitais de conhecidos imigrantes portugueses, como o comendador Salgado Zenha e o conde São Salvador de Matosinhos, ligados ao Banco Comercial do Rio de Janeiro, criado em 1866 (Serra e Rabaça, 2010, p. 116).

Os exemplos não se resumem a esse caso e, na virada do século XX, com a intensificação da chegada de imigrantes de Portugal no Brasil, mais e mais negócios foram criados na cidade. Sobretudo, os bancos com sede em Lisboa passaram a disputar com bancos criados no Brasil o atraente mercado de intermediação de remessas dos imigrantes e o financiamento do movimento de exportação de mercadorias de Portugal para o Brasil. Assim, instalaram-se no Rio de Janeiro os bancos Aliança, Mercantil Português, União, Comércio e Indústria, Banco do Minho, Nacional Ultramarino e o Financial do Rio de Janeiro.

Com igual propósito, no dia 18 de março de 1918, os acionistas do Banco Português do Brasil reuniram-se pela primeira vez em assembleia para aprovar o texto dos estatutos do novo banco. Legalmente, tinha início a empresa. A justificativa para a criação do banco era atender aos interesses e necessidades financeiras do Brasil e de Portugal. De fato, o exame da trajetória do banco mostra que os homens de negócio, nascidos em Portugal, mas enriquecidos no Brasil, apoiaram-se no banco para ampliar seus negócios individuais e, ao mesmo tempo, participar dos lucros da atividade bancária. 
O banco buscou atrair os recursos dos integrantes da comunidade imigrante na forma de depósitos. Ao mesmo tempo, buscava reter parte da renda da grande massa dos trabalhadores imigrantes, tanto através da intermediação de remessas aos familiares em Portugal, quanto através do mercado de incorporação imobiliária.

Em termos formais, os estatutos do banco informam que a empresa foi criada para realizar atividades bancárias, inclusive operar com câmbio, o que não acontecia em todas as instituições bancárias da época. Os estatutos do banco previam também que a instituição poderia assumir o serviço de caixa por conta de particulares e entidades públicas e, assim, os acionistas mostravam disposição em habilitar a empresa a se tornar um agente do governo português na intermediação de remessas de imigrantes, o que de fato aconteceu entre julho de 1919 e junho de 1921 (Pereira, 1981). Nos primeiros 10 anos de existência do banco, as atividades foram ampliadas e foram construídos edifícios-sede em bela arquitetura, no Rio de Janeiro e em Santos. Imagens desses majestosos edifícios ilustraram a obra comemorativa da presença lusa no Brasil, Álbum da Colônia Portuguesa, publicada por Carinhas (1929).

Além de o Banco ocupar um lugar privilegiado na rede empresarial da colônia, seus dirigentes gozavam de forte reputação política, o que influenciou positivamente na trajetória da instituição. O presidente vitalício do banco, José Júlio Pereira de Moraes, era conhecido como Visconde de Moraes e tinha a reputação de deter vasto patrimônio imobiliário na cidade ${ }^{7}$. Moraes associava-se a Jaime Lino Sotto Maior, ligado à produção têxtil e ao comércio de atacado, na promoção de ações caritativas em prol dos imigrantes pobres. Cumpriam eles, assim, o que se esperava de imigrantes bem-sucedidos. A reputação de ambos como benevolentes líderes de instituições de amparo à população imigrante reforçou a imagem positiva do banco como uma instituição sólida e respeitável.

Conforme se argumentou no início deste artigo, a questão da confiança do público poupador sustenta-se na visibilidade do indivíduo, e neste particular o Visconde de Moraes atendia a todos os requisitos. Embora o banco tivesse surgido com a forte participação acionária de integrantes da família Sotto Maior - os irmãos Cândido e Jaime Lino, além do Banco Pinto \& Sotto Maior, com sede em Lisboa - a escolha do Visconde para presidir a organização nunca foi contestada.

A partir desse quadro de pessoas e negócios, o artigo examina ainda nesta seção quem eram os mais influentes acionistas do Banco, como participavam da comunidade imigrante, bem como a natureza das relações políticas que mantinham com integrantes da elite política brasileira nos anos 1920.

\footnotetext{
${ }^{7}$ Visconde de Moraes nasceu em Gouvinhas, no município de Sabrosa, no ano de 1848, e morreu no Rio de Janeiro, em 1931. Ver: www.museu-emigrantes.org.
} 
Como a lei permitia, embora nem todos os bancos adotassem tal medida, o Banco Português do Brasil não exigia dos seus acionistas o depósito integral do valor de suas ações. Previa-se que o restante devido seria completado em chamadas de capital, embora os acionistas passassem a receber dividendos proporcionais àquilo que tivessem colocado no banco. Para o público e para as autoridades monetárias, o valor nominal do capital do banco era elevado, quando de fato ele correspondia à metade.

Em circunstâncias favoráveis, este arranjo atendia aos interesses dos dirigentes do banco e de seus acionistas. Entretanto, em momentos de crise, como nos anos de 1931 a 1933, os acionistas relutaram em colocar mais capital próprio no negócio e a posição financeira do banco ficou frágil. O capital do banco perdia, assim, a finalidade de representar um lastro para suas operações bancárias.

Com tais limitações, o capital social foi estipulado em 1918 em 25 mil contos de réis, representado por 125 mil ações, que foram subscritas $73 \%$ no Brasil e o restante em Portugal. O maior acionista fundador era o banco Pinto \& Sotto Maior, com $7,43 \%$ das ações. Somados, todos os acionistas individuais da família Sotto Maior e empresas de sua propriedade representavam 12,2\% das ações do banco em 1919. Inclui-se entre as empresas do grupo, além do mencionado banco Pinto \& Sotto Maior, a Companhia de Seguros Sagres, ambos com sede em Portugal. Individualmente, eram acionistas Jaime Lino Sotto Maior e Cândido da Cunha Sotto Maior ${ }^{8}$. Os interesses dos Sotto Maior no Brasil se estendiam da produção de têxteis, na Fábrica Corcovado, ao comércio atacadista no Rio de Janeiro, passando pela Seguradora Sagres. Esta última aparece em documentação de 1922 como tendo sede em Lisboa e outro documento, de 1925, já faz menção à sede da empresa no Rio de Janeiro9 ${ }^{9}$ Em Portugal, os Sotto Maior controlavam o banco Pinto \& Sotto Maior, que atuava nas províncias ultramarinas (Angola e Moçambique), e constituíram o líder do grupo investidor que promoveu a eletrificação da cidade do Porto $^{10}$.

Apesar de possuir 6\% das ações do banco, o Visconde de Moraes, José Júlio de Moraes, foi eleito presidente da empresa e assim permaneceu até sua morte, em 1931. O restante do capital era pulverizado entre os 529 acionistas fundadores, no Brasil ${ }^{11}$. Em Portugal, 313 acionistas participaram da fundação do Banco.

\footnotetext{
${ }^{8}$ Arquivo da Junta Comercial da Capital Federal, Prontuários do Banco Português do Brasil.

${ }^{9}$ Diário Oficial da União, 25/5/1922, 26/9/1922.

${ }^{10}$ Acordo coletivo de trabalho entre o Banco Nacional Ultramarino, Banco de Fomento Nacional, Banco Pinto \& Sotto Maior... e o sindicato nacional dos empregados bancários da província de Moçambique, 1971, citado por Câmara (1989).

${ }^{11}$ Lista de acionistas do Banco Português do Brasil, de 22 de maio de 1919, disponível no arquivo da JUCERJA.
} 
Durante o seu longo período à frente do Banco, Moraes em nenhum momento teve sua nacionalidade questionada pelas autoridades financeiras brasileiras. Para as leis brasileiras da época, uma empresa era nacional se fosse constituída no país e mantivesse aqui o centro de suas operações. Somente nos anos do governo Vargas, a legislação passou a considerar estrangeira a empresa administrada por nacionais de outros países ${ }^{12}$.

Ora, os empresários portugueses não enfatizavam sua origem quando em contato com as autoridades brasileiras porque isso não era necessário. Diverso, entretanto, era o seu comportamento quando buscavam espaço no disputado mercado das remessas de imigrantes para Portugal. Sabe-se que essas remessas tinham grande importância para a economia daquele país e para a sustentação das famílias nas localidades que os imigrantes haviam deixado para trás. Eram responsáveis pela monetização da vida rural, pela valorização da propriedade fundiária e tinham impacto positivo sobre o balanço de capitais de Portugal.

Um estudo sobre o movimento de emigração a partir do município de Fafe, região do Minho, revela que a cidade pulsava conforme o estado da economia brasileira e as crises mundiais (Monteiro, 2000, p. 268). Em 1915, a crise da borracha no Brasil teve impacto sobre a localidade e levou o Almanaque de Fafe a comentar que o Brasil - a árvore das patacas - frustrava as expectativas dos imigrantes e dos parentes deixados para trás, sobretudo, mulheres e velhos (Monteiro, 2000, p. 281).

De fato, recentemente o historiador português Rui Pedro Esteves atribuiu um papel central às remessas dos imigrantes portugueses residentes no Brasil para manter o frágil equilíbrio das contas externas de Portugal:

Desde 1889 que a crise política e das exportações de café havia reduzido o fluxo de remessas dos emigrantes brasileiros, que, comum uma das principais fontes de divisas (saques sobre Londres), era instrumental para a estabilidade do cambio. Além disso, essas mesmas divisas eram indispensáveis para o serviço da dívida externa, pelo que o insucesso da colocação do empréstimo de 1890 deixou o Estado com um premente problema de tesouraria. (Esteves, 2003, p. 320)

Ressalve-se que a análise de Esteves enfatiza a dinâmica das transações econômicas entre Brasil e Portugal na segunda metade do século XIX. Ainda assim, há fortes motivos para pensar que nas primeiras décadas do século XX o fluxo das remessas continuou a gerar os efeitos descritos e este mercado constituía uma oportunidade para bons ganhos. É certo que há dificuldades de dados insuperáveis, pois

\footnotetext{
12 Leis de Sociedades Anônimas que regem a atividade bancária também: Decreto no 434, de 1891, e
} Decreto nํㅡㄹ.627, 26 de setembro de 1940. 
as escassas estatísticas publicadas e acessáveis no Brasil não distinguem as remessas de capitais relativas ao comércio de mercadorias das remessas individuais. Entretanto, chama atenção que o relatório do adido comercial português no Brasil, referente ao movimento de 1922 , afirmava que, dos $£ 2,5$ milhões remetidos do Rio de Janeiro, $£ 1$ milhão representava mercadorias portuguesas exportadas para o Brasil e o restante, $£ 1,5$ milhão, tinha por origem a massa de pequenos poupadores residentes na cidade (Pereira, 1981, p. 256). Deste modo, ao menos para o ano de 1923, a remessa dos trabalhadores residentes no Rio de Janeiro e proximidades superava o trânsito de mercadorias entre Portugal e o Brasil.

$\mathrm{Na}$ avaliação do potencial do mercado de remessas de imigrantes há, além desse indício, que se considerar o peso crescente da população de origem portuguesa, de primeira ou de segunda geração, no conjunto dos moradores da cidade do Rio de Janeiro. Pelo recenseamento de 1920, sabe-se que imigrantes lusos representavam 172 mil pessoas, ou 14\% da população carioca (Brasil, 1920; Melo e Marques, 2008). Toda essa massa imigrante, boa parte dela composta por trabalhadores das indústrias, comércio e transporte, consumia produtos portugueses na sua dieta diária e fazia grandes esforços para poupar, fosse para remeter alguma quantia à família deixada em Portugal, fosse para ambicionar adquirir uma habitação ou prosperar em um pequeno negócio. Com tal psicologia, a população imigrante favorecia a expansão dos negócios do Banco Português do Brasil.

A partir de 1895, as quantias remetidas por imigrantes do Brasil chegaram a Portugal, em boa parte, através da Agência Financial do governo português, estabelecida no Rio de Janeiro. Antes da Primeira Guerra, surgiram outras instituições financeiras que buscavam ampliar a participação neste mercado: o Banco Nacional Ultramarino, fundado em 1913, e com filiais nos estados de São Paulo, Pernambuco, Pará e Amazonas (Carinhas, 1929, p. 174). Como já se comentou, entre 1ํo de julho de 1919 e junho de 1921, o Banco Português do Brasil obteve a vitória política de monopolizar a intermediação de remessas do Brasil para Portugal.

Como indicador do desempenho do banco ao longo do período, apresentamos no quadro abaixo o movimento de depósitos. Essa informação é mantida no seu valor nominal, pois o objetivo da série é mostrar o ingresso e a saída de depósitos no Banco. Pela tabela, vê-se que, já no seu primeiro ano de funcionamento, 1918, o ingresso de depósitos foi expressivo. Por outro lado, vê-se a crise sofrida pelo banco entre 1930 e 1937. 
Tabela 1 - Banco Português do Brasil: Depósitos de curto

\begin{tabular}{|c|c|}
\hline \multicolumn{2}{|c|}{ e de longo prazos } \\
\hline Ano & Depósitos (contos de réis) \\
\hline 1918 & $36.611,51$ \\
\hline 1919 & $57.797,37$ \\
\hline 1920 & $77.651,89$ \\
\hline 1921 & $76.524,96$ \\
\hline 1922 & $101.785,16$ \\
\hline 1923 & nd \\
\hline 1924 & nd \\
\hline 1925 & nd \\
\hline 1926 & $72.092,27$ \\
\hline 1927 & $65.417,12$ \\
\hline 1928 & $64.850,67$ \\
\hline 1929 & $55.981,94$ \\
\hline 1930 & $50.228,80$ \\
\hline 1931 & $33.072,91$ \\
\hline 1932 & $28.785,61$ \\
\hline 1933 & $31.942,92$ \\
\hline 1934 & nd \\
\hline 1935 & nd \\
\hline 1936 & $38.891,25$ \\
\hline 1937 & $42.724,99$ \\
\hline 1938 & $58.095,00$ \\
\hline 1939 & $90.721,24$ \\
\hline 1940 & $139.529,00$ \\
\hline 1941 & $202.991,35$ \\
\hline
\end{tabular}

Nota: nd - dados não disponíveis.

Fonte: Elaboração própria com dados dos balanços anuais publicados no Diário Oficial e na Revista Bancária Brasileira.

Nos primeiros anos, o volume de depósitos cresceu regularmente. Como termo de comparação, tomemos os depósitos do Banco Nacional Ultramarino, maior competidor do Banco Português no mercado da colônia portuguesa no Rio de Janeiro. Em 1918, vê-se que o Banco Português captou 36 mil contos, enquanto o Ultramarino recebeu 53 mil contos. No ano seguinte, o Banco Português captou a mais que o Ultramarino, que recebeu $57.300 \operatorname{contos}^{13}$. Motivados por esse quadro positivo, os diretores do banco contrataram uma empresa para construir o edifício-sede da empresa, localizado em um endereço comercial nobre no centro da Capital Federal, o que tornava visível a capacidade empreendedora do elemento luso. Além

${ }^{13}$ Para conhecer o movimento financeiro do Banco Nacional Ultramarino, veja-se o Diário Oficial, $13 / 01 / 1920$ 
disso, se tomarmos a cidade de Nova York como termo de comparação, os negócios bancários de imigrantes atingem novo patamar de credibilidade quando se materializa a sede própria em local de grande circulação de pessoas. Isso porque os moradores daquela cidade, em mais de uma vez, viram bancos locais surgirem, captarem depósitos e fecharem as portas inexplicavelmente, deixando os depositantes atônitos (Van Horn, 2010).

Para demarcar o compromisso dos dirigentes com a condução do banco e, ao mesmo tempo, celebrar a prosperidade da comunidade imigrante no Rio de Janeiro, o local escolhido para erguer o majestoso edifício-sede do Banco Português foi a Rua da Candelária, no coração da cidade. Em 1919, o banco construiu também edifícios com semelhante apuro, onde instalou filiais em São Paulo e em Santos, regiões exportadoras de café e que também abrigavam importantes colônias de imigrantes lusos ${ }^{14}$. Quanto ao peso das filiais no desempenho econômico do banco, pouco se pode dizer por que os balanços anuais apresentam resultados consolidados, não sendo possível distinguir o movimento das praças no Rio de Janeiro, do movimento das praças paulistas.

Ainda em 1919, o banco promoveu a elevação do capital de 25 mil contos para 50 mil contos, sob a justificativa de desejar realizar operações em longo prazo. Entretanto, a política de não obrigar os acionistas a depositar a quantia integral de suas ações permaneceu. Com essa manobra, Moraes assumiu o controle acionário do banco, com $15 \%$ das ações.

Além das implicações de moral hazard que sugere a extraordinária elevação do capital nominal do banco, o exame da evolução do patrimônio líquido (PL) da empresa no período anterior à crise dos anos 1930 revela que os resultados do banco não cresceram na mesma proporção (Marques, 1998). Em sendo o PL composto pela soma do capital nominal com reservas e essas últimas, provenientes da retenção do lucro social, a série do PL no período não apresenta comportamento similar ao do capital, elevado em 100\%, em 1919. Ora, se as reservas não contribuíram na mesma proporção que o valor do capital para o crescimento do PL, pode-se conjecturar que ou os dirigentes do banco não foram capazes de encontrar suficientes operações geradoras de receitas, ou distribuíram lucros aos acionistas na forma de dividendos. Essas são apenas conjecturas, pois a documentação investigada não permite traçar o perfil

\footnotetext{
${ }^{14}$ Em escala decrescente de importância demográfica, as seguintes cidades reuniam colônias de imigrantes portugueses: Rio de Janeiro, Niterói, São Paulo, Santos, Belém, Salvador e Recife. Ver Lobo (2001).
} 
da política de distribuição de lucros entre os participantes no negócio, tampouco a historiografia serve de apoio para deslindar a questão ${ }^{15}$.

Pode-se não saber se os acionistas foram beneficiados com regulares distribuições de lucros, mas é sabido que foram beneficiados com crédito barato, pois, logo no início de 1920, a fábrica de tecidos Corcovado, de propriedade da família Sotto Maior, recebeu um empréstimo de nove contos de réis, ou cerca de $£ 676 \mathrm{mil}^{16}$. Com o empréstimo, a fábrica Corcovado pretendia comprar a massa falida de outra empresa de tecidos, a Andaraí, fabricante de tecidos de lã. Essas operações ilustram a teia de negócios estabelecida no seio da comunidade de negócios portugueses e a rede bancária.

Não foi essa, por certo, a única ocasião em que uma empresa financeira da comunidade portuguesa concedeu empréstimos a um integrante do seu próprio corpo de acionistas, em uma clara operação de inside lending. Muitos anos antes, em 1890, um banco chamado Cooperativo ofereceu capital e participou da criação de uma empresa produtora de cerveja - a Cooperativa de Cerveja. Segundo consta no Decreto $\mathrm{n}^{\mathrm{o}}$ 437, de 31 de maio de 1890, participava desse banco o Visconde de Moraes. Assim, embora não fosse uma operação comercial incomum, o empréstimo do Banco Português a uma empresa dos Sotto Maior causou mal estar no mercado, pois o banco precisou vir a público argumentar que o empréstimo era garantido de modo seguro ${ }^{17}$.

Ao contratar o empréstimo, os Sotto Maior calculavam que o mercado de tecidos iria se recuperar da concorrência dos similares ingleses que entravam no Brasil desde a Primeira Guerra a preços baixos. No entanto, essa previsão econômica não se concretizou e os negócios da família Sotto Maior no ramo têxtil apresentaram crescentes déficits ao final dos anos $1920^{18}$.

Outro ramo de negócios em que o Banco Português do Brasil atuou foi o de incorporação imobiliária no Rio de Janeiro, então a capital do país. Será esse o principal mercado onde se formaram fortunas nos anos 1930, mas a documentação revela que os homens de negócio ligados ao Banco Português já atuavam neste mercado desde muito antes. Houve uma empresa, de nome Companhia Parque da Várzea do Carmo,

\footnotetext{
${ }^{15}$ Sugere Sochaczewski (1993) que a atividade bancária no Brasil foi um dos ramos de negócio bastante lucrativo quando se considera a evolução real do capital do sistema bancário nas primeiras décadas da industrialização. As autoras também fizeram detalhado exame contábil dos balancetes do banco com o Professor Silvando Cardoso, técnico do Banco Nacional do Desenvolvimento Econômico e Social e professor da Universidade Federal Fluminense. Desse exercício, constatou-se não ser possível afirmar com segurança qual a política de distribuição de lucros do banco.

16 Taxa de câmbio de 13,31 por mil réis, para 1919 (IBGE, estatísticas históricas).

${ }^{17}$ Diário Oficial, dias 20, 25, e 31 de janeiro de 1920.

${ }^{18}$ Balanço da Fábrica de Tecidos Corcovado. Diário Oficial, 17/03/1927.
} 
criada simultaneamente ao Banco e com os mesmos acionistas, embora os dirigentes do banco sempre tivessem negado vínculo com a empresa. Era uma dentre as muitas cooperativas imobiliárias existentes na cidade, que coletavam depósitos e sorteavam crédito imobiliário. A Várzea do Carmo mantinha operações no Rio de Janeiro e na cidade de São Paulo, onde foi responsável pela incorporação de vastas regiões em torno do mercado municipal da capital paulista.

Nos anos 1930, a Várzea do Carmo foi objeto de forte crítica na imprensa sob a alegação de fraude contra a economia dos poupadores. A propaganda da empresa anunciava pequenos empréstimos individuais destinados à compra de terrenos ou à construção de imóveis. Este apelo atraía os poupadores, mas os críticos acusavam a empresa de beneficiar indústrias sob o disfarce de muitos pequenos empréstimos que, somados, resultavam em grandes somas, conforme noticiado pelo Jornal Correio da Manhã (Correio da Manhã, 1934).

Outro grande negócio envolvendo incorporação imobiliária foi o contrato de saneamento da Baixada Fluminense, firmado entre o Governo da União, o Banco e o acionista Jerônimo Teixeira. Ao final de 1920, Teixeira assumiu junto ao Governo Federal, com apoio do banco, o contrato de saneamento de extensa região em torno da Baía da Guanabara, subúrbios da cidade, segundo consta no Decreto ${ }^{\circ} 14.588$, de 30 de dezembro de 1920. O acordo previa que o Governo Federal depositaria no banco 45 mil contos de réis em apólices federais para sustentar as obras de saneamento. Em contrapartida, os participantes da nova empresa - Melhoramentos da Baixada Fluminense - podiam incorporar terrenos nas novas regiões saneadas. Da nova empresa, participaram o Visconde de Moraes, vários integrantes da família Sotto Maior e o engenheiro responsável pela empresa e acionista do banco, Jerônimo Teixeira. Para o Banco Português, o empréstimo concedido pelo Governo Federal ampliava o lastro de suas habituais operações de crédito. Além disso, havia a expectativa de lucros elevados com operações imobiliárias.

Assim como o negócio da firma Melhoramentos da Baixada Fluminense não poderia se concretizar sem que os diretores do banco tivessem proximidade política com as autoridades públicas, outra iniciativa de Moraes chama atenção por revelar canais políticos estreitos entre a comunidade de negócios portuguesa e as autoridades brasileiras. Logo em 1922, o banco incorporou a Manufatura Nacional de Porcelanas, destinada a produzir material elétrico para compor postes de iluminação, a serem fornecidos ao Governo Federal ${ }^{19}$.

${ }^{19}$ Ver Carinhas (1929). Essa fábrica foi instalada no bairro do Cachambi, onde, posteriormente, funcionou a fábrica Klabin. Hoje, todos os terrenos foram incorporados ao Norte Shopping. 
Esses eram os mais importantes investimentos diretos do banco no Rio de Janeiro. No entanto, a comunidade de negócios portuguesa na cidade se estendia desde pequenos negócios de varejo, especialmente no comércio de alimentos, no transporte por carroças, até numerosas indústrias. Em verdade, a comunidade portuguesa se mesclava com a própria vida da cidade, especialmente, no comércio de varejo e de atacado. Os Sotto Maior tinham a Sotto Maior \& Cia., empresa atacadista de tecidos e comercial-importadora. Affonso Vizeu, presidente da Associação Comercial, estava à frente de uma empresa atacadista de mesmo nome. Segundo Carinhas (1929) e Lobo (1978), entre as fábricas de tecidos de grupos empresariais de origem portuguesa, havia, além da mencionada Fábrica Corcovado, a Bangu, da família Guilherme da Silveira, a perfumaria Granado, e a Cervejaria Hanseática, de Zeferino de Oliveira ${ }^{20}$.

\section{A CRISE DE 1929}

A crise econômica que se anunciou em 1928 e assumiu feições graves no ano seguinte atingiu severamente as empresas comerciais da cidade, especialmente àquelas ligadas ao comércio de importação. Em retrospectiva, o intercâmbio comercial entre Portugal e o Brasil foi de 227 milhões de escudos, em 1922, ou $£ 2$ milhões ao câmbio da época, conforme informou o Adido Comercial Português ${ }^{21}$. Em 1928, o intercâmbio comercial caiu para 136 milhões de escudos, em 1929 chegou a 120 milhões, e no ano de 1930 somou apenas 111 milhões de escudos (Brasil, 1931).

Como o ramo de atividade do grande comércio importador não se recuperou nos anos 1930, marcados por profunda depreciação do valor da moeda brasileira na primeira metade da década, as famílias cujo patrimônio estava envolvido com esse setor se voltaram para outros negócios, principalmente o mercado interno. Já as indústrias de alimentos, passado o momento mais grave da crise, expandiram suas atividades, dessa vez em um mercado protegido. Só um setor não se recuperou da crise e da concorrência dos produtos estrangeiros, que foram as indústrias têxteis. Ao longo da segunda metade do século XX, as unidades fabris lentamente foram desativadas para dar lugar a loteamentos nos terrenos, a exemplo do patrimônio dos Sotto Maior e mesmo de Manoel Guilherme da Silveira.

\footnotetext{
${ }^{20}$ Zeferino de Oliveira, importante industrial, principal acionista da Cervejaria Hanseática, principal concorrente da Cervejaria Brahma no Rio de Janeiro, também era acionista, em Portugal, do banco Pinto \& Sotto Maior.

${ }^{21}$ Relatório do Adido Comercial de Portugal para 1923, citado por Pereira (1981, p. 44).
} 
É de se esperar que a diminuição do dinamismo dos negócios na comunidade dos imigrantes atingisse o Banco Português. De fato, isso aconteceu e agravou os passivos trazidos da década de 1920, especialmente, o endividamento com a Melhoramentos da Baixada e a Manufatura Nacional de Porcelanas.

Logo em fevereiro de 1930, os acionistas do banco se reuniram para discutir a situação da empresa e a reforma dos estatutos. Principalmente, a diretoria levou aos acionistas a proposta de completarem o valor restante de suas ações, sob a justificativa de permitir que as ações fossem alienáveis a preços melhores ${ }^{22}$. Essa razão parece não ter convencido os acionistas, que relutaram em colocar capital próprio em um negócio que apresentava riscos, quando seus próprios negócios requeriam capital. Ao longo do ano de 1930, a direção do banco fez todo o esforço para manter a aparente normalidade dos negócios e evitar uma corrida aos caixas, embora o movimento de depósitos tenha claramente diminuído. Também foi preciso renegociar a dívida com a União, a respeito do negócio da empresa Melhoramentos da Baixada.

Em 1931, o Visconde de Moraes morreu e a empresa Melhoramentos da Baixada entrou em liquidação judicial. Conforme registrado no Decreto no 20.256, de 25 de julho de 1931, o novo governo não aceitou a renovação do contrato e a extensão do prazo para a conclusão das obras de saneamento e propôs a execução dos terrenos incorporados pela empresa como parte do pagamento do empréstimo de 1920. Poucos anos depois, o Governo Federal criou uma empresa pública de saneamento da mesma região onde a Melhoramentos da Baixada deveria ter feito as obras (Soares, 1962).

Sem a liderança do Visconde de Moraes, com sua elevada reputação junto à comunidade imigrante e seu trânsito com as autoridades brasileiras, o banco passava por maus momentos. Dos antigos acionistas nenhum aceitou assumir a direção do banco após a sua morte, pois todos estavam envolvidos em salvar suas próprias empresas, a exemplo de José Lino Sotto Maior ${ }^{23}$. Também o quadro político havia mudado drasticamente após a Revolução de 1930, que depôs o governo liberal e instaurou o governo de Getúlio Vargas.

Diante dessa situação, o filho do Visconde de Moraes assumiu a direção do banco e buscou mantê-lo em operação. Assim, a direção solicitou ao Ministério da Fazenda a redução do capital nominal do banco de 50 mil para 20 mil contos, o que trouxe o capital da empresa à sua real situação.

O movimento de depósitos declinou ao longo da década e os créditos de difícil recuperação pesaram sobre a solvência do banco. O impacto disso sobre o valor das

\footnotetext{
${ }^{22}$ Registro da Assembleia Geral de Acionistas, em 8 de fevereiro de 1930, disponível no Arquivo da JUCERJA.

${ }^{23}$ Relatório anual da Companhia Corcovado, publicado no Diário Oficial, 26 de março de 1932.
} 
ações foi irremediável, pois, em junho de 1937, uma ação ao portador do Banco Português estava cotada a 95 mil réis, enquanto que uma ação de um banco concorrente, o Boavista, era negociada a 610 mil réis (O Observador Econômico e Financeiro, 1937).

Para os antigos acionistas, o investimento no banco não mais representava um bom negócio, mas havia outros empresários na cidade interessados em comprar o banco, atraídos por seu maior ativo: o histórico de vínculo com a comunidade portuguesa. Para isso, era preciso aumentar a credibilidade da empresa no mercado a fim de atrair depósitos. Assim, um grupo ligado a negócios imobiliários, indústrias e antigos proprietários de armazéns gerais no porto aproveitou o baixo valor das ações para assumir o controle do banco ${ }^{24}$. Ainda assim, como era típico no Banco Português, a distribuição das ações continuou a ser bastante descentralizada. O quadro acionário foi reestruturado em outubro de 1938, com destaque para Antônio de Almeida Braga e Ernesto Garcides Fontes ${ }^{25}$.

Os estatutos do banco foram então alterados para admitir explicitamente como objeto comercial a aquisição e venda de imóveis, o que se apresentava como uma oportunidade de negócios em face da expansão dos bairros do Flamengo, de Copacabana, a perspectiva de ampla reformulação do centro, além de vastas regiões dos subúrbios ${ }^{26}$. Entretanto, como operação bancária, o financiamento imobiliário apresenta riscos mais elevados do que o financiamento do comércio de mercadorias, por exemplo.

Almeida Braga insistiu junto ao novo conselho de administração para que o banco ampliasse o investimento imobiliário, mas encontrou resistência. Braga acabou por vender suas ações e deixar o banco em 1943, para se dedicar à Companhia Atlântica de Seguros, empresa que fundara em 1937. Então, Braga pode realizar o plano de intensificar o projeto de empresa financeira associada ao negócio imobiliário. Isso porque, se a legislação bancária apenas admitia o comércio imobiliário como uma atividade suplementar ao negócio, a legislação de seguros, dado o seu viés nacionalista, obrigava as seguradoras a investir suas reservas técnicas em propriedades reais.

\footnotetext{
${ }^{24}$ Raimundo de Castro Maia era empresário industrial. Antônio Leite Garcia era proprietário de uma empresa de engenharia com contratos com o Governo Federal. Ernesto Garcides Fontes atuou no ramo de comércio atacadista até a crise de 1930 e neste momento ingressava no setor bancário. Antônio Carlos de Almeida Braga vinha de uma família de origem portuguesa, mas nasceu em São Paulo. No Banco Português do Brasil, foi acionista e administrador da empresa Várzea do Campo. Casou-se com a filha de Joaquim Nabuco, integrante da elite do Império e da Primeira República.

${ }^{25}$ Ficha de filiação do Banco Português do Brasil ao Sindicato dos Bancos do Estado do Rio de Janeiro, de 16 de novembro de 1940, citado por Banaskiwitz e Hegybeli (1946, p. 667).

${ }^{26}$ Banco Português do Brasil, Assembleia Geral Extraordinária, em 28 de outubro de 1938, disponível no arquivo da JUCERJA.
} 
Como, além da reforma dos estatutos, houve mudanças expressivas nos quadros dirigentes do banco, a credibilidade da instituição foi lentamente se recuperando e os depósitos voltaram a fluir. É certo que, após 1930, a intermediação de remessas de imigrantes deixou de constituir um importante ramo de atuação bancária na cidade do Rio de Janeiro. Entretanto, a população residente de origem portuguesa constituía um mercado potencial expressivo e o fluxo migratório, ainda que tivesse se reduzido, não cessou totalmente.

\section{CONSIDERAÇÕES FINAIS}

Cabe fazer um balanço da trajetória do Banco Português e ressaltar que o perfil dos acionistas e dos investimentos do banco mudou sensivelmente nos 20 primeiros anos de existência da organização. Em retrospecto, percebe-se que a trajetória do banco refletiu a dinâmica dos negócios na cidade do Rio de Janeiro. Na etapa inicial, prevaleciam entre os acionistas os empresários ligados ao grande comércio atacadista, a exemplo dos Sotto Maior. Havia industriais entre os primeiros acionistas, por certo, mas essa categoria de empresários assumiu o controle do Banco apenas na fase posterior à sua reestruturação em 1938. Só um traço comum une o banco antes e depois de 1938: a importância do investimento imobiliário na acumulação privada do empresariado. Com uma expressiva diferença: figuras como o Visconde de Moraes haviam construído sua fortuna a partir de investimentos variados, com destaque nos negócios imobiliários, pois uma das fontes consultadas se refere a Moraes como proprietário de ruas inteiras nos subúrbios do Rio de Janeiro (Beneficência Portuguesa, 1990, p. 103).

No entanto, nos anos 1930, o rentier urbano deu lugar às empresas imobiliárias, que atuaram em grande escala como grandes incorporadores do solo urbano da cidade. De fato, as disponibilidades do recém-criado sistema previdenciário provocaram no Rio de Janeiro, nos anos 1940, uma bolha especulativa com imóveis que abriu amplas oportunidades de negócio, mas abalou seriamente o sistema financeiro (Machado, 1947). Os tempos dos ganhos com o comércio externo haviam passado. Os empresários da comunidade portuguesa que acumularam maior fortuna nos anos que seguiram à crise de 1929 foram os que acompanharam a expansão do mercado interno, a exemplo de Antonio de Almeida Braga e de Raimundo de Castro Maia.

Além das mudanças impostas pela crise provocarem a alteração no perfil dos negócios da comunidade empresarial portuguesa, também as alianças com a elite política brasileira tiveram que ser refeitas, pois o poder mudou de mãos drasticamente após 1930. Nisso, os dirigentes à frente do Banco Português após 1938 se mostraram mais hábeis do que o grupo controlador anterior. Por último, essa análise aponta que 
outros negócios surgiram com a mudança estrutural vivida pela economia na década de 1930 e provavelmente isso explica a troca do comando do Banco Português do Brasil, mas há indícios de que todos os sócios auferiam ganhos, seja por lucros, seja por crédito barato ao longo das décadas avaliadas por este estudo.

\section{APÊNDICE}

Figura 1 - Foto do edifício-sede do Banco Português do Brasil*

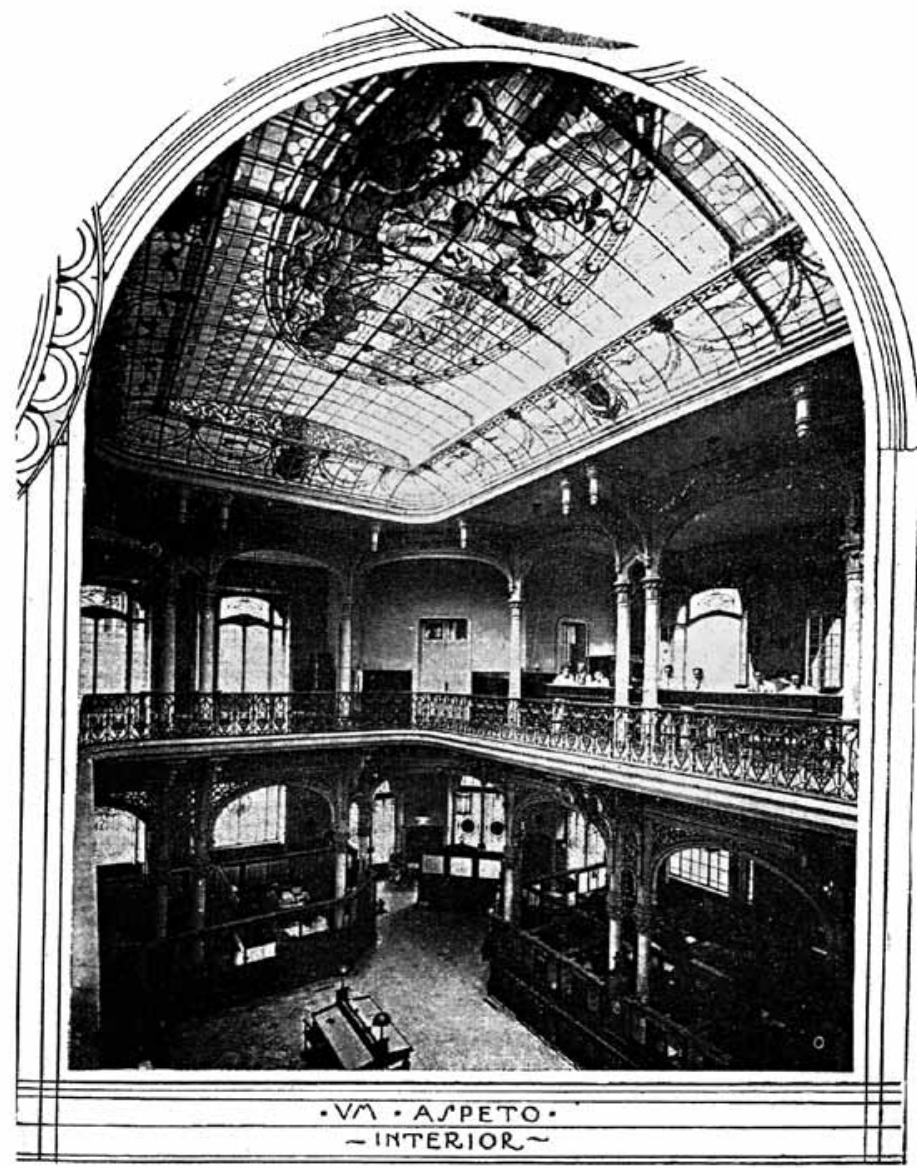

*Imagem reproduzida com a gentil permissão do Real Gabinete Português de Leitura - Rio de Janeiro. As autoras agradecem à direção desta entidade.

Fonte: Carinhas (1929). 


\section{REFERÊNCIAS}

\section{Fontes primárias}

BRASIL. Departamento Nacional de Comércio. Boletim, 1931.

BRASIL. Diário Oficial da União. Fábrica de Tecidos Corcovado, Relatório Anual. 26/03/1932. . Fábrica de Tecidos Corcovado, Balanço. 17/03/1927. . Companhia de Seguros Sagres, Ata da Assembléia Geral Extraordinária. 30/12/1925. . Companhia de Seguros Terrestres e Marítimos Sagres, Ata da Assembléia Geral Extraordinária. 14/09/1925.

. Decreto n. 15.401, de 17/03/1922, Aprova as alterações nos estatutos daCompanhia de Seguros Terrestres e Marítimos Sagres. 25/05/1922.

. Companhia de Seguros Terrestres e Marítimos Sagres, Ata da Assembléia Geral Extraordinária. 25/05/1922. . Relatório do Banco Nacional Ultramarino. 13/01/1920.

JORNAL CORREIO DA MANHÃ, 18/05/1934.

JUNTA COMERCIAL DO RIO DE JANEIRO (JUCERJA). Arquivo Histórico da Junta Comercial do Capital Federal. Rio de Janeiro, s/d. . Prontuários do Banco Português do Brasil, 1918-1947. Rio de Janeiro, s/d.

MACHADO, J. V. “Exposição sobre a situação bancária”. Arquivo Histórico do Banco do Brasil, Rio de Janeiro, 13/12/1947.

REVISTA O OBSERVADOR ECONÔMICO E FINANCEIRO, junho de 1937.

SINDICATO DE BANCOS DO ESTADO DO RIO DE JANEIRO. Prontuários do Banco Português do Brasil. Arquivo. Rio de Janeiro, s/d.

SINDICATO DE BANCOS DO ESTADO DO RIO DE JANEIRO. Prontuários do Banco Itaú. Arquivo. Rio de Janeiro, s/d.

\section{Fontes secundárias}

BANASKIWITZ, G.; HEGYBELI, E. (Orgs.) O livro das Sociedades Anônimas Brasileiras período de 1943 a 1945. Históricos, relatórios e balanços de 4500 Cias em todo o território nacional. São Paulo: Siciliano, 1946. [Suplemento de Que é o Senhor?]

BANCO PINTO E SOTTO MAIOR. Banco Pinto \& Sotto Maior: 50 anos ao serviço da economia nacional. Lisboa: Banco Pinto e Sotto Maior, 1964.

BENEFICÊNCIA PORTUGUESA. Testemunha benemérita da história do Rio de Janeiro. Rio de Janeiro: Golden Cross, 1990.

BRASIL. IBGE (Instituto Brasileiro de Geografia e Estatística). Recenseamento Geral do Brasil. Vol. II, $1^{\text {a }}$ parte, 1920. p. L e LVIII. 
. Estatísticas Históricas do Brasil, Séries Econômicas, Demográficas e Sociais de 1550 a 1985. Rio de Janeiro, 1985.

CARINHAS, J. Álbum da colônia portuguesa. Rio de Janeiro: Gráfica Carinhas, 1929. Disponível no acervo do Real Gabinete Português de Leitura. Rio de Janeiro, s/d.

CAMARA, J. História do Banco Pinto \& Sotto Maior, 1914-1989. Lisboa: Banco Pinto e Sotto Maior, 1989.

CEPESE (Centro de Estudos da População). Economia e Sociedade, População e Sociedade, n. 14 e $15,2001$.

DAY, J. Credit, capital and community: informal banking in immigrant communities in the United States, 1880-1924. Financial History Review, v. 1, n. 9, 2002, p. 65-78.

ESTEVES, R. Finanças públicas. In: LAINS, P.; SILVA, A. História Econômica de Portugal, 1700-2000. Volume II. Lisboa: Imprensa de Ciências Sociais, 2003.

HAHNER, J. Poverty and politics: the urban poor in Brazil, 1870-1970. Albuquerque: University of New Mexico Press, 1986.

LOBO, E. História do Rio de Janeiro. Do capital comercial ao capital industrial e financeiro. Rio de Janeiro: IBMEC, 1978.

. Migração Portuguesa no Brasil. São Paulo: Hucitec, 2001.

MACARINI, J. P. A política bancária do regime militar: o Projeto de Conglomerado (1967-1973). Texto para Discussão, EI/UNICAMP, n. 124, jan., 2007.

MADUREIRA, N. Crédito e mercados financeiros em Lisboa. Ler História, Lisboa, n. 26, 1994, p. 21-43.

MARQUES, T. C. N. O setor bancário privado carioca entre 1918 e 1945. Os Bancos Boavista e Português do Brasil - um estudo de estratégias empresariais. Universidade Federal do Rio de Janeiro, Dissertação de Mestrado em História, 1998.

MARQUES, T. C. N.; MELO, H.; ARAÚJO, J. L. Raça e nacionalidade no mercado de trabalho carioca na Primeira República: o caso da cervejaria Brahma. Revista Brasileira de Economia, v. 3, n. 57, 2003, p. 535-568.

MATOS, M. I. Deslocamentos e História: os portugueses. Bauru/Porto: EDUSC/CEPESE, 2008

MELO, H.; MARQUES, T. C. N. Imigrantes portugueses no Brasil a partir dos recenseamentos populacionais do século XX: um estudo exploratório de gênero. Niterói: Gênero, v. 9, n. 1, 2. Sem., 2008, p. 69-88.

MONTEIRO, M. Migrantes, emigrantes e brasileiros, 1834-1926. Fafe: Instituto de Ciências Sociais da Universidade do Minho, 2000.

PEREIRA, M. A política portuguesa de emigração. Lisboa: A Regra do Jogo, 1981.

ROCHA, M. Entre nós a basta a palavra: as práticas informais de crédito na investigação histórica. Ler História, Lisboa, n. 41, 2001, p. 161-182. 
SAES, F. Crédito e bancos no desenvolvimento da economia paulista, 1850-1930. São Paulo: IPE/ USP, 1986.

SERRA, M.; RABAÇA, C. (Orgs) De pai para filho: imigrantes portugueses no Rio de Janeiro. Rio de Janeiro: Documenta Histórica Editora, 2010.

SOCHACZEWSKI, C. Desenvolvimento econômico e financeiro do Brasil, 1952-1968. São Paulo: T. Cultural, 1993, p. 135.

SMITH, J. E. Family connections: a history of Italian and Jewish immigrant lives in providence, Rhode Island, 1900-1940. Albany: State University of New York Press, 1985.

SOARES, M. T. S. A integração do Recôncavo da Guanabara na área metropolitana do Grande Rio de Janeiro. Revista Brasileira de Geografia. Rio de Janeiro, abril/junho, 1962.

SOUSA, F. “A emigração do Norte de Portugal para o Brasil: uma primeira abordagem (18341950)”. In: MATOS, M. et al. Deslocamentos \& Histórias: os Portugueses. Bauru: Edusc, 2008, p. 27-34.

TAVARES, M.; ASSIS, J. O grande salto para o caos. Rio de Janeiro: Jorge Zahar, 1986.

TRINER, G. Banking and economic development: Brazil, 1889-1930. New York: Palgrave, 2000.

VAN HORN, P. “The Small, Private Banker in New York and Regulatory Change, 1893-1933”.

Essays in Economic \& Business History, Bucknell University Press, v. XXVIII, 2010, p. 107-121.

\section{Site}

Museu da Emigração e das Comunidades. Página eletrônica: www.museu-emigrantes.org. Acesso em março de 2010. 